\title{
Analysis of Combustion Efficiency for Turbofan Engine Combustor Using MATLAB
}

\author{
Yasin Şöhret, Önder Turan, and T. Hikmet Karakoç
}

\begin{abstract}
The thermal efficiency of an aircraft turbofan engine is related to combustion efficiency.It is net output thrust power to total input fuel energy of the combustor.However, net heat effects on thermal efficiency and net heat is related to combustion efficiency.Furthermore, specifying combustion efficiency has a key role inestimating emission indices. In this study, the combustion efficiency of a turbofan engine combustor is analyzed by MATLAB. In the program codes,the basic combustion equilibrium is analyzed for carbon, hydrogen, oxygen, nitrogen, sulfur, carbon dioxide, carbon monoxide, hydrocarbon, nitrogen oxide, nitric oxide and water.As a conclusion, researchers examinethe relationship between combustion efficiency and exhaust gas emissions.
\end{abstract}

Index Terms-Combustion efficiency, turbofan engine, emissions, sustainable aviation, environment.

\section{INTRODUCTION}

At the present time, emission values are seen as important criteria for the investigation of environmental effects. Emission data measured from aircraft engines are compared with regulations and improvements are sustained [1]-[3]. Another emphasis of emission values is to obtain an opinion about combustion in the combustion chamber. As known, the ingredients of exhaust gases provide ideas about combustion proximity to stoichiometric combustion.

Thermodynamically, the thermal efficiency of a thermal system is net output energy ratio to total input energy [4]. If we apply this to an aircraft engine we can express thermal efficiency of an engine as the ratio of net output work to combustion heat value. However, net heat produced by combustion effects on thermal efficiency directly and net heat is related to combustion efficiency. That is, the thermal efficiency of an aircraft engine is also related to combustion efficiency.

At this moment in time, developing more efficient aircraft engines that consume less fuel is a key objective. In this context, determining combustion efficiency experimentally can contribute to these improvements [5], [6]. Determining combustion efficiency experimentally is used to compare results with design efficiency. Comparing these values can show us the condition of a working engine and therefore a maintenance schedule can be constructed. If this procedure is applied to a new engine design, at the end of tests, design faults can be detected.

Manuscript received April 10, 2014; revised June 19, 2014. This work was supported by the TUSAS Engine Inc. and is a development of work carried out on a collaborative project with Anadolu University.

The authors are with Anadolu University, School of Graduate Sciences, Airframe and Powerplant Maintenance Department, TR-26470, Eskisehir, Turkey (e-mail: ysohret@gmail.com, onderturan@anadolu.edu.tr, hikmetkarakoc@gmail.com).
When we check open literature, we can see familiar studies however, no similar study could be found. Many researchers studied emission measurement and combustion efficiency determination methods from gas turbine engines heretofore. In Poland, some researchers studied the development of special probes for the measurement of emissions from aircraft engines [7]. In this study, researchers examined the measurement of different parameters, one is exhaust gas emissions. Kaminaga and other researchers analyzed exhaust emissions in their study [8]. In this, emissions data was analyzed and variation of different parameters was handled. At NASA Lewis Research Center, researchers examined the performance of a modular turbojet combustion chamber [9]. Within the scope of this study, mathematical models are used to explain the relationship between exhaust gas emissions and combustion efficiency. This method is similar to the mathematical model explained in our study. In another research carried out by NASA, the effect of two different fuels on exhaust emissions in an aircraft engine combustor are investigated [10]. The performance parameters and emissions variations of the combustor are examined according to Jet A and diesel fuels. Pourmovahedet al. studied a jet engine. In this research the researchers examined engine performances and performance parameters at various pressures, temperatures and fuel flow. Additionally, efficiencies for each component of the engine were calculated and measured, this measurement data and calculation results were then compared and examined by the researchers. As a result of this study, researchers proved the performance characteristics of the engine [11]. In another study, researchers examined emissions variations of a gas turbine engine [12]. Lebedevet et al., modeled a gas turbine combustor on CFD and analyzed emission variations on CFD. These results are also validated by an experimental combustor using methane and kerosene as fuel. As a result of this experimental study, researchers estimated the increase of inlet temperature, decreases $\mathrm{CO}$ and UHC emissions. Erbogosoet et al., examined an industrial gas turbine with a thermodynamically approach and analyzed $\mathrm{CO}, \mathrm{UHC}, \mathrm{NO}_{\mathrm{x}}$ emissions [13]. In this study, researchers measured the different emissions data from the gas turbine and explained the variations of emissions by temperature and fuel flow. Datta and Som examined the emission characteristics of a gas turbine combustor at different pressures and swirl conditions [14]. In this research, emissions variations, EGT and combustion efficiencies are measured and calculated for different workloads. Also a numerical model of liquid fuels pray com bustioninagasturbinecombustor was developed by researchers to analyze the influence of inlet swirl number and combustion pressure on combustion and emission characteristics. 
Through this study, researchers examined relations between combustion efficiency and exhaust gas emissions. Thus, the basic combustion equilibrium is analyzed and related to emission indices. This analytical method is adapted to Matlab programming language and researchers developed COMEFF (Combustion Efficiency) software to calculate combustion efficiency of any type of gas turbine engine by using emissions data.

\section{METHOD}

\section{A. Mathematical Model}

To relate emission data to combustion efficiency, firstly we need to analysis the basic combustion equilibrium in the combustion chamber. Equation (1) can be written for one mole of fuel and air [15]

$$
\begin{gathered}
\mathrm{C}_{m} \mathrm{H}_{n} \mathrm{O}_{p} \mathrm{~N}_{q} \mathrm{~S}_{r}+X\left[R\left(\mathrm{O}_{2}\right)+S\left(\mathrm{~N}_{2}\right)\right. \\
\left.+T\left(\mathrm{CO}_{2}\right)+h\left(\mathrm{H}_{2} \mathrm{O}\right)+U\left(\mathrm{CH}_{4}\right)\right] \\
\rightarrow A_{1}\left(\mathrm{CO}_{2}\right)+A_{2}\left(\mathrm{~N}_{2}\right)+A_{3}\left(\mathrm{O}_{2}\right) \\
+A_{4}\left(\mathrm{H}_{2} \mathrm{O}\right)+A_{5}(\mathrm{CO})+A_{6}\left(\mathrm{C}_{x} \mathrm{H}_{y}\right) \\
+A_{7}\left(\mathrm{NO}_{2}\right)+A_{8}(\mathrm{NO})+A_{9}\left(\mathrm{SO}_{2}\right)
\end{gathered}
$$

At Equation (1) $A_{1}$ through $A_{9}$ are the number of moles $\mathrm{CO}_{2}, \mathrm{~N}_{2}, \mathrm{O}_{2}, \mathrm{H}_{2} \mathrm{O}, \mathrm{CO}, \mathrm{C}_{x} \mathrm{H}_{y}, \mathrm{NO}_{2} \mathrm{NO}$ and $\mathrm{SO}_{2}$.

By further derivations, the equations given below can be written for the equilibrium of carbon, hydrogen, oxygen, nitrogen, sulfur, carbon dioxide, carbon monoxide, hydrocarbon, nitrogen oxide, nitric oxide and water respectively [15]:

$$
\begin{gathered}
m+(T-U) X=A_{1}+A_{5}+\mathrm{x} A_{6} \\
n+(2 h+4 U) X=2 A_{4}+y A_{6} \\
p+(2 R+2 T+h) X=2 A_{1}+2 A_{3}+A_{4} \\
+A_{5}+2 A_{7}+A_{8}+2 A_{9} \\
q+2 S X=2 A_{2}+A_{7}+A_{8} \\
r=A_{9} \\
A_{1}=A\left[\mathrm{CO}_{2}\right]_{w} \\
A_{5}=A\left[\mathrm{CO}_{w}\right. \\
x A_{6}=A\left[\mathrm{C}_{x} \mathrm{H}_{y}\right]_{w} \\
A_{7}+A_{8}=A\left[\mathrm{NO}_{x}\right]_{w} \\
A_{8}=A\left[\mathrm{NO}_{w}\right. \\
A_{4}=A\left[\mathrm{H}_{2} \mathrm{O}\right]_{w}
\end{gathered}
$$

For the equations given, " $A$ " means total mole number of products as shown at Equation (13):

$$
A=A_{1}+A_{2}+A_{3}+A_{4}+A_{5}+A_{6}+A_{7}+A_{8}+A_{9}
$$

Equations (4) through (15) are written according to direct measurement data. For these equilibrium equations, analyzer interferences and calculation correction coefficients are not taken into consideration. If we know analyzer interferences and calculation correction coefficients, the derived equations are given below [8], [15]:

$$
\begin{aligned}
& A_{5}=A[\mathrm{CO}]_{m s}+A_{1} C_{\mathrm{CO}_{2} \rightarrow \mathrm{CO}}+A_{4} C_{\mathrm{H}_{2} \mathrm{O} \rightarrow \mathrm{CO}} \\
& A_{7}+A_{8}=A\left[\mathrm{NO}_{x}\right]_{m s}+A_{1} \mathrm{C}_{\mathrm{CO}_{2} \rightarrow \mathrm{NO}+\mathrm{NO}_{\mathrm{x}}} \\
& +A_{4} C_{\mathrm{H}_{2} \mathrm{O} \rightarrow \mathrm{NO}+\mathrm{NO}_{x}} \\
& A_{8}=A[\mathrm{NO}]_{m s}+A_{1} C_{\mathrm{CO}_{2} \rightarrow \mathrm{CO}}+A_{4} C_{\mathrm{H}_{2} \mathrm{O} \rightarrow \mathrm{CO}} \\
& A_{1}=A\left[\mathrm{CO}_{2}\right]_{m s}+A_{3} C_{\mathrm{O}_{2} \rightarrow \mathrm{CO}_{2}}
\end{aligned}
$$

For Equations (14) through (17); “ $C_{a \rightarrow b}$ ” shows interference coefficient of a on the measurement of $b$. During emissions measurements, chemiluminescent analyzers can be used. These type of analyzers can measure the concentration of nitric oxide and nitrogen oxides. Theoretically, the concentration of nitrogen dioxide equals the difference between nitric oxide and nitrogen oxide. For these analyzers, converter efficiency is defined and is notated by " $\eta$ ". If we continue derivations by implicating this converter efficiency, we can find this corrected equation [8], [15]:

$$
A\left[\mathrm{NO}_{x}\right]_{m s}=\eta A_{7}+A_{8}
$$

" $h_{s d}$ " is defined as water content of the sample exhaust gases after dryer and calculated as given in Equation (19) [15]:

$$
h_{s d}=\frac{A_{4 s d}}{A-A_{4}}
$$

If we conflate derived equations as a matrix system, the solution can be simplified. After solving this equation set, the emission indexes are calculated. The emission index of variable $Z$ can be calculated as given in Equation (20) [15]:

$$
\begin{gathered}
E I_{Z}=1000\left(\frac{\text { mass rate of } Z}{\text { mass rate of fuel }}\right) \\
=\frac{\text { moles of } Z}{\text { moles of fuel }} \cdot \frac{\text { molecular weight of } Z}{\text { molecular weight of fuel }} \cdot 1000
\end{gathered}
$$

Depending on this equation emission indexes can be derived [15]:

$$
\begin{gathered}
\frac{A_{5} \cdot 28,0104 \cdot 10^{3}}{m(12,011+(1,008 \cdot(n / m)))} \\
E I_{\mathrm{C}_{x} \mathrm{H}_{y}}=\frac{x \cdot A_{6} \cdot M_{\mathrm{C}_{x} \mathrm{H}_{y} \cdot 10^{3}}}{m(12,011+(1,008 \cdot(n / m)))}
\end{gathered}
$$

" $M_{\mathrm{C}_{x} \mathrm{H}_{y}}$ " connotes molecular weight of unburned hydrocarbon gases in exhaust gases. Equation (23) is written for carbon monoxide and unburned hydrocarbons respectively.

According to these equations, combustion efficiency can 
be calculated as given below [15]:

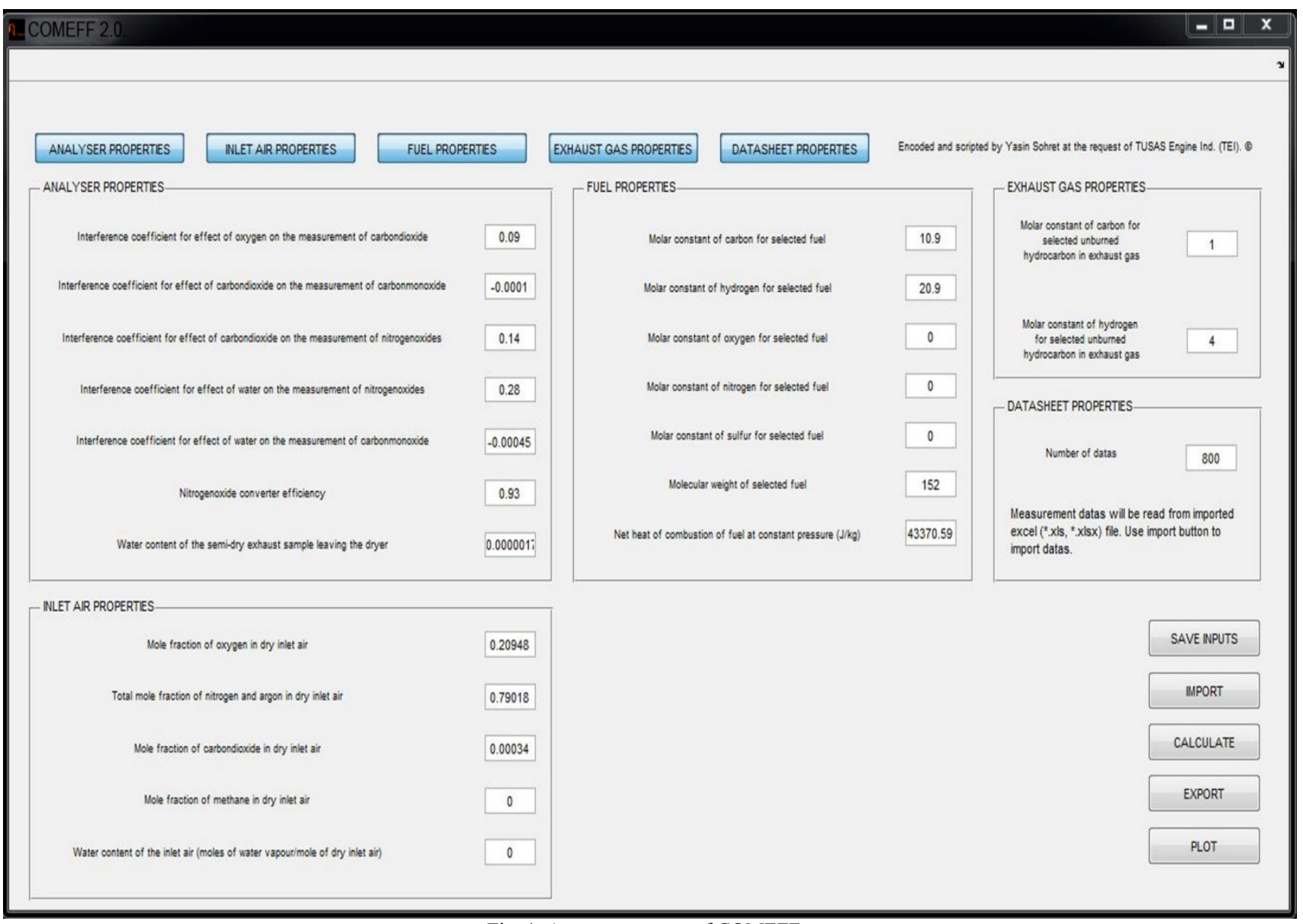

Fig. 1. A screen capture of COMEFF.

$$
\eta_{b}=100\left(1-10.109 \frac{E I_{\mathrm{CO}}}{H_{f}}-\frac{E I_{\mathrm{C}_{x} \mathrm{H}_{y}}}{1000}\right)
$$

In Equation (23), $H_{f}$ denotes net heat of fuel. Equation 23 is current for net heat of fuel as $\mathrm{J} / \mathrm{kg}$.

By this method, the combustion efficiency in a gas turbine combustion chamber can be calculated.

\section{B. Coding}

COMEFF software allows theuser to calculate the combustion efficiency of any gas turbine engine usingemission data. The critical point is that COMEFF doesnot have a data quantity limit. Measurements per second bring about 1000 data output during a test for 10 minutes. In this situation, calculating combustion efficiency manually takes a long time. COMEFF has features to calculate combustion efficiency, export results on MS Excel file and plot results.

COMEFF software is encoded and scripted in Matlab language. The first version of software, was released on 23 July 2012. By 20 September 2012 this version was no longer approved. On 5February 2013the second version was released with a new user interface, illustrated in Fig.1.

This interface consists of six subsections. First is the analyzer properties section. The user is required to input specifications of the analyzer which was used during measurement. The second subsection includes inlet air properties. These values are measured from the inlet point of the gas turbine engine.
The fuel properties necessary to run COMEFF. In this section, the user is required to input the characteristic properties of the fuel used for combustion in the gas turbine. Another subsection is used to input the properties of exhaust gases. The user specifies the unburned hydro-carbon gases in exhaust gases and inputs these values in to COMEFF. In this interface of COMEFF data number, the number of rows in MS-Excel file to be read by COMEFF is determined by user.

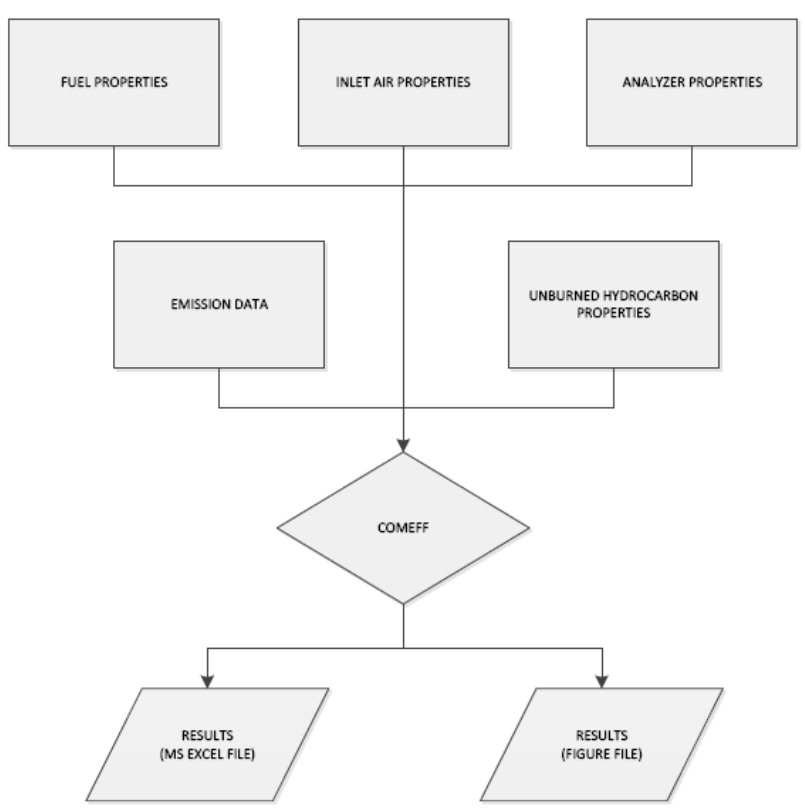

Fig. 2. Flowchart of COMEFF software. 
A button group is in the bottomright corner of the COMEFF interface. The first button, named "SAVE INPUTS", is used for saving screen input data in a buffer. Usersare able to show the path of the MS-Excel file by using the "IMPORT" button. When a user clicks on the "CALCULATE" button, COMEFF begins to calculate the combustion efficiency for each data group on the MS-Excel file. Depending on the user's requests, the results are written to an MS-Excel file and can be saved using a desired file name by using the "EXPORT" button. Clicking on the "PLOT" button, allows usersto see the results as a graphin the COMEFF window and save this from the pop-up window.

COMEFF software is based upon a numerical model improved from "Procedure for the Analysis and Evaluation of Gaseous Emissions from Aircraft Engines" named standard which was released by Society of Automotive Engineers (SAE) on 2004. The software's flowchart is illustrated below in Fig. 2.

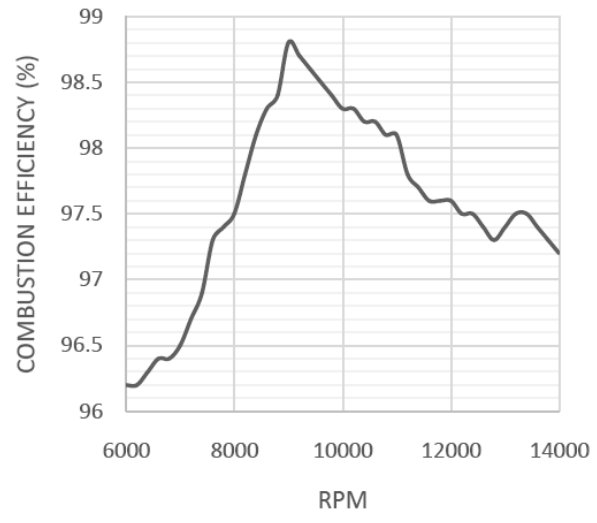

Fig. 3. RPM versus combustion efficiency.

\section{RESUlts AND CONCLUSION}

The final release of COMEFF was used to check emission data from different types of turbofan engines. Before tests, the calibration of the analyzer was controlled and all necessary properties of the analyzer were recorded. Additionally, the fuel used for tests, JP-8, was analyzed in a chemical laboratory to determine the fuel's properties for the calculations. Unburned hydrocarbon is accepted as methane $\left(\mathrm{CH}_{4}\right)$. After these steps, while running engine inlet air properties and all emission values were measured and conveyed from the analyzers to the workstation computer by data cables. This measurement data was saved as an MS-Excel file and imported to COMEFF. As a result of these tests on a turbofan engine, the figure given in Fig. 3was obtained.

When we examine Fig. 3, the combustion efficiency varies between $96.33 \%$ and $98.51 \%$. As we know, theoretically combustion efficiency is $99 \%$ at the most. It has also been observed that experimental studies demonstrate the combustion efficiency for a micro class aircraft engine varies between $75 \%$ and $98 \%$ [13]. When we compare the result given by COMEFF and other experimental studies, the COMEFF results are acceptable. The oscillation at the data curve is a consequence of the variation of fuel mass flow during tests. During rapid RPM increases, combustion and combustion efficiency oscillates until the mass flow becomes balanced. Also, when we examine the corrected curve, we can see similar oscillation as a result of same reason.
In this study, a piece of industrial software based on theoretical combustion equations named COMEFF, was developed and coded by the researchers to determine the combustion efficiency of any type of aircraft engine with emission data. COMEFF software was coded by Matlab programming language and checked by several test measurements from different types of turbofan engines.

With future improvementsof this software, the environmental effects of aircraft engine emissions can easily be determined.

\section{ACKNOWLEDGMENT}

This study was funded by the TUSAS Engine Inc. and is a development of work carried out on a collaborative project with Anadolu University. The authors are very grateful both for their support and invaluable assistance.

\section{REFERENCES}

[1] J. P. Beck, C. E. Reeves, L. F. De, and S. A. Penkett, "The effect of aircraft emissions on tropospheric ozone in the northern hemisphire," Atmospheric Environment, vol. 26, no. 1, 1992.

[2] S. H. Lee, M. L. Dilosquer, R. Singh, and M. J. Rycroft, "Further considerations of engine emissions from subsonic aircraft at cruise altitude", Atmospheric Environment, vol. 30, no. 22, 1996.

[3] U. Kergin, "Aircraft emissions at turkish airports," Energy, vol. 31, 2006.

[4] Y. Cengel and M. Boles, Thermodynamics an Engineering Approach 5th Edition, USA: McGraw-Hill Higher Education, 2006.

[5] T. Nikoleris, G. Guptab, and M. Kistler, "Detailed estimation of fuel consumption and emissions during aircraft taxi operations at dallas/fort worth international airport," Transportation Research Part D: Transport and Environment, vol. 16, no. 4, 2011.

[6] A. H. Epstein, "Aircraft engines' needs from combustion science and engineering," Combustion and Flame, vol. 159, no. 5, 2012.

[7] Z. M. Romicki and S. Zurkowski, Special Probes for Measurements of Flow Parameters in a Gas-Turbine Engine, Poland.

[8] A. Kaminaga, T. Horikawa, H. Nakamura, K. Isobe, S. Higashijima, N. Miya, and T. Tanabe, Analysis of Exhausted Gas in JT-60 Deuterium Operation, Japan.

[9] N. R. Murchionnu and M. T. Arthur, Experimental Performance of $A$ Modular Turbojet Combustor Burning Natural Gas Fuel, Washington, D. C., USA: National Aeronautics and Space Administration, 1970.

[10] R. D. Ingebo and C. T. Norgren, Combustor Exhaust Emissions With Air-Atomizing Splash-Groove Fuel Injectors Burning Jet A And Diesel Number 2 Fuels, Washington, D. C., USA: National Aeronautics and Space Administration, 1975.

[11] A. Pourmovahed, C. M. Jeruzal, and K. D. Brinker, "Development of a jet engine experiment for the energy systems laboratory," in Proc. ASME International Mechanical Engineering Congress, 2003.

[12] A. B. Lebedev, A. N. Secundov, A. M. Starik, N. S. Titova, and A. M. Schepin, "Modeling study of gas-turbine combustor emission," in Proc. the Combustion Institute, vol. 32, 2009.

[13] E. M. M. Orbegoso, C. D. Romeiro, S. B. Ferreira, and L. F. F. da Silva, "Emissions and thermodynamic performance simulation of an industrial gas turbine," Journal of Propulsion and Power, vol. 27, no.1, 2011.

[14] A. Datta and S. K. Som, "Combustion and emission characteristics in a gas turbine combustor at different pressure and swirl conditions," Applied Thermal Engineering, vol. 19, 1999.

[15] Procedure for the Calculation of Gaseous Emissions from Aircraft Turbine Engines, SAE Aerospace Standard ARP1533-2004.

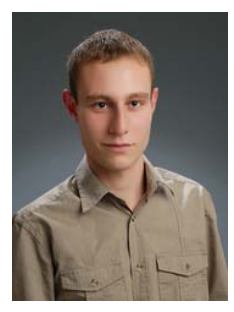

Söhret Yasin was born in Antalya, Turkey in 1986 He graduated from Mechanical Engineering Department of Engineering and Architecture Faculty of Eskisehir Osmangazi University in 2010. He still continues his $\mathrm{PhD}$ education at Anadolu University after getting $\mathrm{MsC}$ degree from Civil Aviation Department. Şöhretmainly studies gas turbine engine measurements, combustion and fuels, energy and exergy analysis of thermal systems, energy saving technologies, renewable energy technologies. 


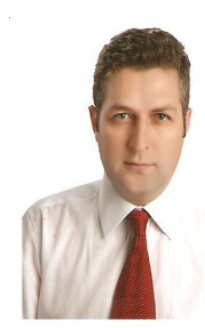

Önder Turan is an assoc. prof. in the Faculty of Aeronautics and Astronautics. He received his BScand MSc in the School of Civil Aviation and Graduate School of Sciences at Anadolu University in 1998 and 2000, Respectively. He received his $\mathrm{PhD}$ in 2007 under the supervision of Dr. HikmetKarakoç. He has published many papers at various national and international conferences. He is also a member of many journals and associations. His research areas

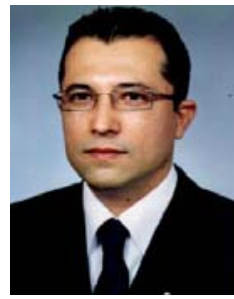

T. Hikmet Karakoc is a full professor of Faculty of Aeronautics and Astronautics at Anadolu University, Eskisehir, Turkey. He received his MSc and PhD in 1983 and 1987, respectively. He has published many papers at various national and international conferences, while he has authored several books. He is also a member of many journals and associations. His research areas include aviation, energy and energy economy, gas turbine engines, fuels, isolation and installation.

gas turbine engines, aircraft propulsion systems and fuels. 